\title{
Adapted Performance Sportswear
}

\author{
Alexandra DE RAEVE, Simona VASILE \\ FTI Lab*, University College Ghent, Ghent, Belgium \\ DOI: $10.15221 / 16.009 \quad$ http://dx.doi.org/10.15221/16.009
}

\begin{abstract}
Sportswear is based on sizing tables developed on a basis of average body sizes and will therefore not fit population groups with body proportions categorically different from average (e.g. athletes from different sport disciplines, disabled people or people with specific professions). This is not only detrimental for the aesthetics and comfort of the wearer but also in stark contrast with functionality (e.g. orthopedic products; sportswear meant to offer some support, to improve performance or to facilitate fast revalidation; some intelligent textiles for monitoring) and the changing demands of the consumers who lose their tolerance for regular products and have become more and more demanding for garments with a personalized fit. These groups of products require an optimal contact with the skin, they have to fit, otherwise they lose their functionality.

The overall objective of the project Adapted Performance Sportswear is to develop comfortable, fitted and functional (sports)wear for population groups with body shapes and proportions different from the average population. The aim of the project is to gain better insight in anthropometric differences (average population versus various groups of athletes) and work out a methodology for translating this information effectively to the garment production. The concept of compression, support and restriction of certain movements by employment of new and innovative elastic materials will be further explored in relation to the fit.
\end{abstract}

Keywords: sportswear, mass customization, fit, 3D body scanning

\section{Introduction}

The current textile markets offer textile products in a number of sizes. However, these are based on more or less average body proportions. Nevertheless, some population groups have categorically different body proportions. Except for "made-to-measure" garments, the same guidelines and body measurements tables are used for these population groups as for the average population. Figure 1 shows the body form variance and intercept of the hip of three subjects with the same $(\Delta \leq 2 \mathrm{~cm})$ bust, waist and hip girth. All of them would wear the same garment size in Belgium.
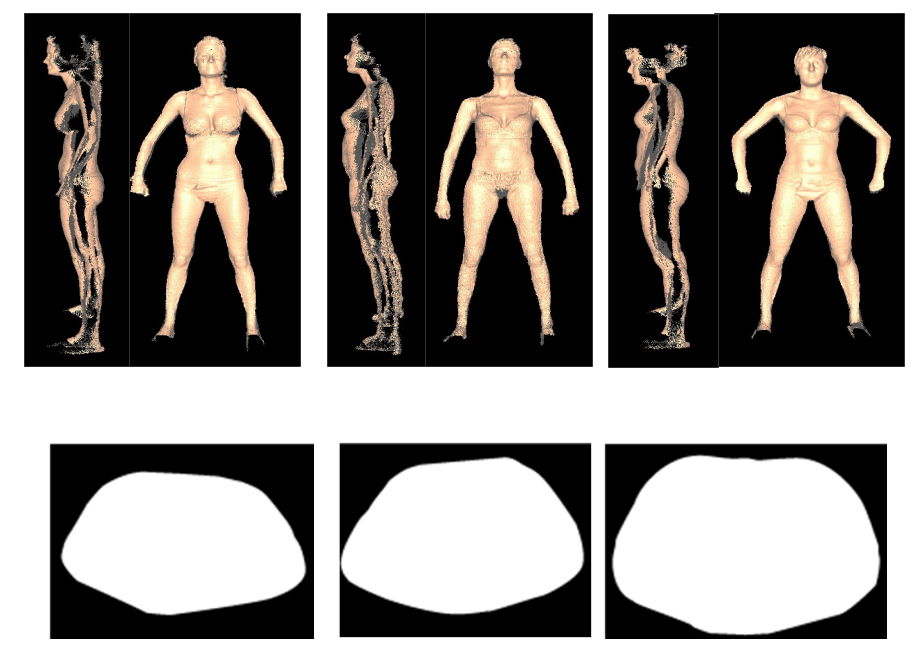

Figure 1 Body form variance in the same size 
It is obvious how differing the body forms are and that it is impossible to dress all of them with the same garment. Especially sports athletes show fundamental differences in body measurements compared to the average population (e.g. Figure 2). Corresponding to their sports discipline they develop bigger circumferences in body regions like bust, upper arm, thighs and calf. To satisfy customers' needs it is evident for producers to know about the specific body proportions of the target group.

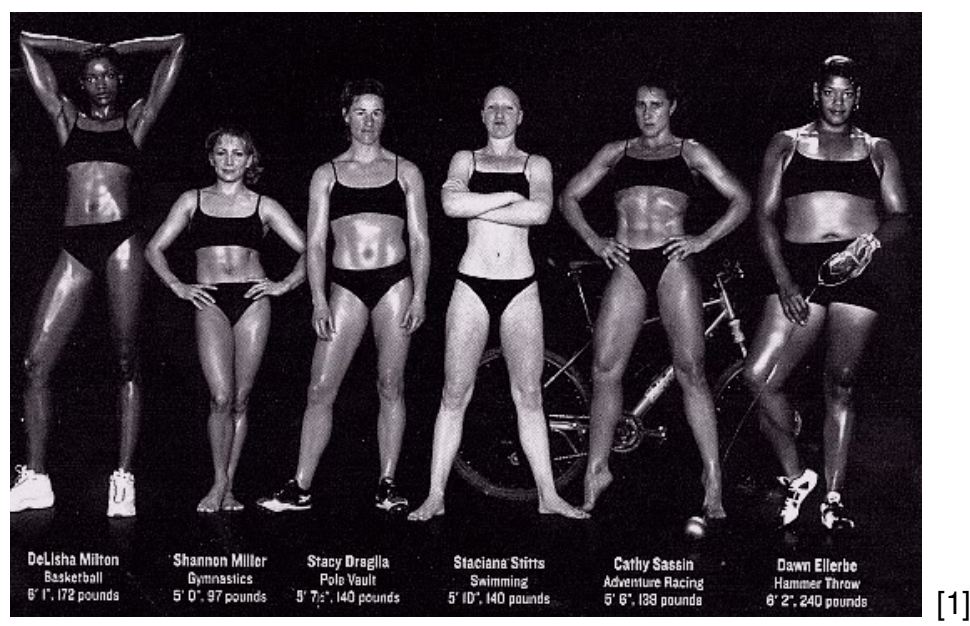

Figure 2 Body form variance of female athletes corresponding to sports discipline

Another problem that occurs in clothing development for athletes is, that muscle movement significantly increases or decreases circumferences and lengths.

Table 1 Body measurement alterations due to muscle strain [2]

\begin{tabular}{|c|c|c|c|c|c|c|c|}
\hline 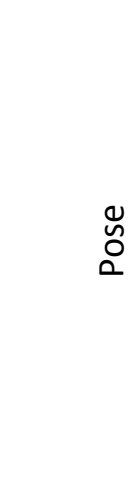 & 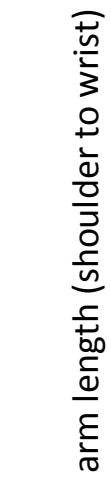 & 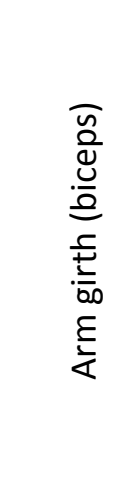 & 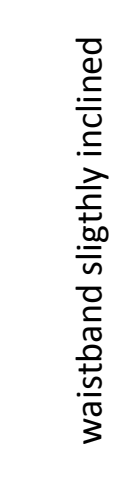 & 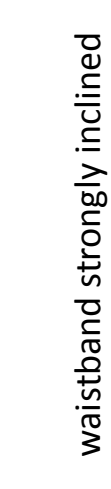 & 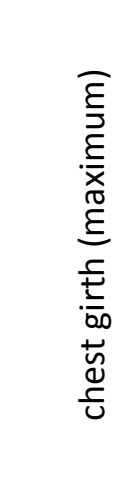 & 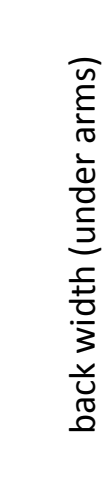 & 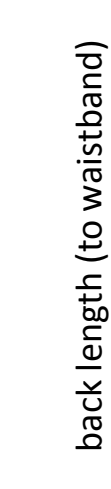 \\
\hline strained & 64 & 26.8 & 85.4 & 85.4 & 110.6 & 44.1 & 48.5 \\
\hline relaxed & 59.1 & 32 & 84.9 & 94.7 & 106.8 & 37.7 & 52.4 \\
\hline
\end{tabular}

If for instance a trained subject strains its muscles during exercise e.g. back width may increase up to $6.5 \mathrm{~cm}$ and arm length may increase with $5 \mathrm{~cm}$. Each size has a scope of $4 \mathrm{~cm}$, which means that this small movement leads to a difference of almost two sizes. Sports garments have to ensure great freedom of movement and perfect fit although body dimensions show these clear alterations. This is not only detrimental to the wear comfort and aesthetics but also to performance as the desired functionality will not be achieved in case of wear performance and intelligent clothing. Research has shown that in fact, compression / supportive clothing yields only result when the fit is perfect and the functional material is incorporated in the right place. For instance, a well-fitting speed wear can lead to 134 seconds profit over a cycling distance of $40 \mathrm{~km}$ [3]. With this project we will gain better insight in these traditional anthropometric differences and work out a methodology for translating this information effectively to the garment production. We will further explore the concept of compression, support and restricting certain movements. 


\section{Research approach}

\subsection{Fit of sportswear, 3D Body scanning}

Standards exist for size designation of different types of clothes, for women, men or children [4]. Nevertheless, these standards are based on body measurements of average populations and no standards exist for sportswear for specific sport disciplines. During the last decade national measurment campaigns have been conducted in Belgium (e.g. SMARTFIT 2013), Germany (e.g. SizeGERMANY 2007-2009), and many other countries such as the UK Spain and The Netherlands. Measurement tables for average populations have been updated. Most companies offer sizes on the basis of up to three body heights, which covers at best about $31,3 \%$. As depicted in figure 4 , another important aspect is the change in body form with age.

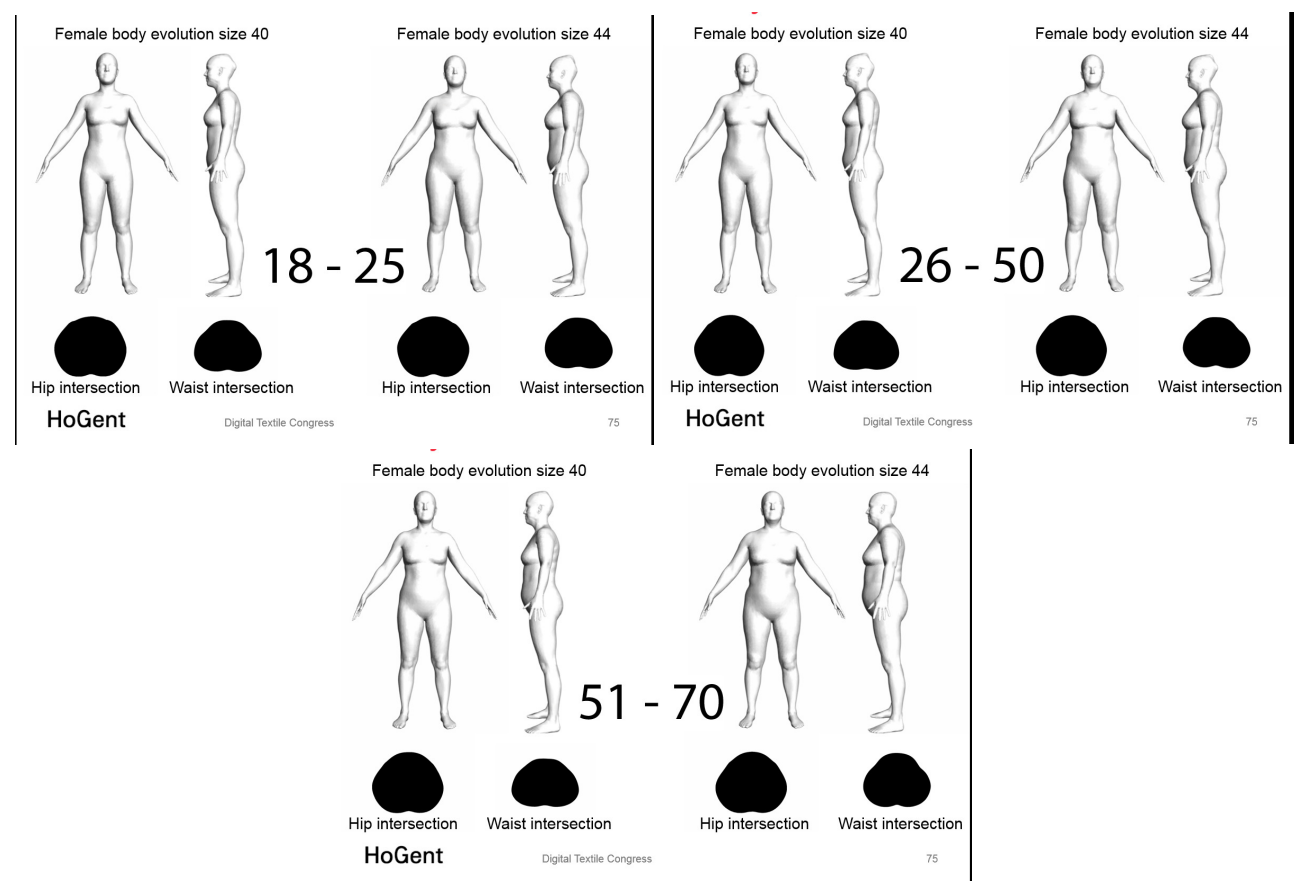

Figure 3 Changes in body form corresponding to age

For target groups with body proportions that differ from the average special sizing charts are needed. Therefore, measuring campaigns for different groups (e.g. big size women and men, wheelchair athletes) were conducted in some countries and sizing tables were developed [5] [6] [7] [8]. Studies [9] have analyzed 3D body scans of athletes from various sport disciplines (e.g. basketball, golf, volleyball) and highlighted statistical significant differences between body dimensions of male athletes and average population but no sizing tables have been developed for sportswear.

In former days body measurements were taken manually with measuring tapes, which was time consuming. To take some measurements like inseam (floor to crotch) it was awkward or even unpleasant for subjects. Nowadays, 3D Body Scanning is state of the art and used in the latest sizing surveys because of diverse benefits. These are:

- Fast and non-contact acquisition of a large group of subjects [10]

- Fast and comprehensive measuring due to specialized software

- Reliable and reproducible measurements

- Minimized interpersonal errors

- No transmission errors because of automatic data flow in evaluation software

- Verifiable results

- Plausibility check with measurements and 3D data

- Comprehensive analysis: Posture, cross section, posture comparison, 3D inspection of surface changes, volume analysis

- Base for generating digital average body forms for use in common 3D CAD software 
Nevertheless some limitations applying to high accuracy booth scanners should be taken into consideration such as: high prices; insufficient mobility; subject is scanned in underwear.

It has been shown that movement leads to major measurement differences [11] [12] [13]. As shown in figure 3 torso length increases due to bending over $12,3 \mathrm{~cm}$. The dimension waist to hip contoured is increasing $7,1 \mathrm{~cm}$. These extensions have to be covered especially by sports garment. Therefore, it is important to understand the human body in motion. Clothing construction has to take into account the typical measurement changes of athletes [14] [15]. It may be assumed that especially athletes show significant differences due to a higher muscle mass. Analysis showed strong distinctions in circumfernces like bust and upper arm [7]. Latest research projects concentrate on measurement differences of sportsmen and movement in clothes [16] [17]. The results indicating and makeing it clear, that 3D Scanning technology is an appropriate and most expedient approach to investigate body measurements and their alterations due to movement. But the focus was only on the lower body. Moreover, there was a small amount of subjects scanned. The results were not integrated into measurement charts. To develop garments with less or even no restriction of movement, it has to be investigated how and to which extend dimensions change in the target groups. The changes have to be integrated into the special measurement tables as a basis for optimized dicipline specific sports compression garments. Therefore, a bigger group of sportsmen in several diciplines has to be caputered in relaxed and in specific postures. Thus, data records can be devided into size clusters to extract significant primary and secondary measurements and to generate reliable measurement charts.

\subsection{Compression clothing}

Sports garment with compressional function are very common, especially in endurance sports. Athletes wish to improve their performance by wearing compression socks, tights, tubes and shirts. Functions to achieve are e.g. better blood reflow to the heart, faster recuperation and less muscle movement [18] [19] [20]. There are a few studies concerning performance improvement but with diverse results. Some proved the benefit [21], others did not [22] [23]. In these studies textile construction was not a main task. All the more, it is evident to investigate optimized pattern construction and testing methodes to foster companies in compression garment development. The power of sportswear with elastomeric fibers originates from understanding of the relationship between garment compression and muscle performance. An athleste's force and power production wearing a compression garment was higher than with a loose fitting garment. Furthermore athletes increased the accuracy of their movements or body positioning [24]. The use of these garments as a recovery tool, while doing exercise may be beneficial to reduce post-exercise trauma and perceived muscle soreness [24]. However, caution should be taken while choosing the correct compression garment for the right sports and ensuring that the garment provides enough pressure to promote vebous return. Only if it is understood how and where compression works and increases or supports sports performance, SMEs will be able to develop functional and wellfitting compression garments. The examination of the compressive behaviour of sports garments is not completely investigated. However, for medical compression hosiery there are guidelines that define quality and testing (s. RAL-GZ 387/1, RAL-GZ 387/2, DIN 58133:2008-07, BS 6612 en BS 7563). Both German and British standards are refering to dynamometric methods that assess the value of pressure on the leg wearing a stocking. At the moment EMI is devloping a measuring system that assesses the pressure peformed on leg's muscles and veins. The device consists of 2 silicone legs with different morphology. The legs are provided with artificial muscles and veins. This method also allows to assess the influence of various elastic materials in one product.

\subsection{Comfort of sportswear}

Functionality is important but wearing comfort, too. The comfort of clothing is determined by the thermophysiological and skin sensorial properties of the fabric. Newly developed textile materials have to be analyzed with regard to the skin sensation e.g. soft, hard, sticky, cold or cosy and thermal sensation. The thermoregulatory properties describe the heat and moisture management of textile materials. They are defined by thermal insulation, water vapour transmission (breathability), air permeability, water penetration resistance and repellence and liquid sweat management [25]. For certain parameters a choice of test methods is available, some being more appropriate than others with regard to the large differences in the conditions of use. Water vapour resistance is determined with a sweating guarded hot plate, so called "skin model", whereas water vapour permeability can be determined with the inverted cup method. Liquid sweat management can be assessed with a Moisture Management Tester (MMT) (Figure ). This method allows assessing how moisture is being transported throughout a textile material and spread on the inner and outer surface from where it can evaporate. 
Another possibility is to make use of the Hohenstein method BPI 1.2.1. Thermal resistance is measured with a guarded hot plate (Figure 11), whereas thermal conductivity can be measured with the Fabric Touch Tester.

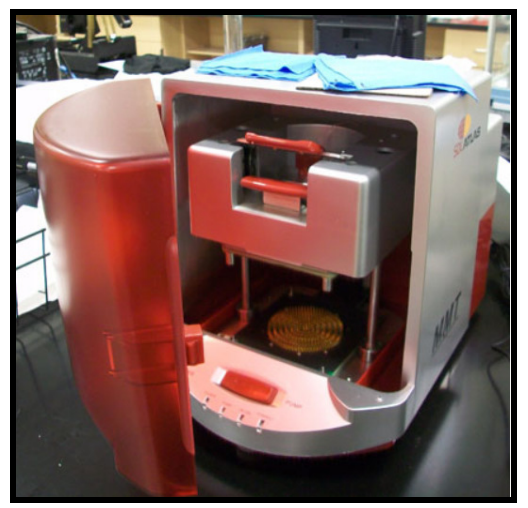

Figure 4 Moisture Management Tester MMT (HoGent, company SDL Atlas)

The determination of the skin sensorial perception or comfort is generally based on the work of expert hand panels en wearer trials. On the other hand the Fabric Touch Tester FTT measures simultanuously 13 fabric indices (related to stifness, bending, compression, friction, roughness and thermal conductivity) on both sides and warp/weft direction and then calculates fabric attributes such as softness, smoothness, warmness, total hand and total touch. First results of the Belgian/German CORNET project TOUCHE confirm a good correlation between FTT results and expert hand panels.

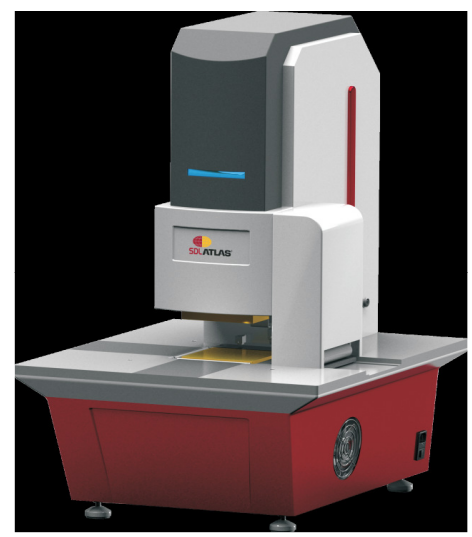

Figure 5 Fabric Touch Tester (HoGent/UGent, company SDL Atlas)

The stretching of the fabrics can change the contact of the fabric with the human skin caused by additional pressure to the skin. The results of the German AiF-project 16868N which investigated only sport compressive socks (sweatmanagement was characterized by means of sweating guarded hotplate under different stretch ratios) show that further investigation is needed [26]. Also wetting of the material due to heavy sweating during exercice will influence certain parameters such as air permeability, friction, thermal conductivity, etc. Verdu et al. (2009) [27] analyzed the effect on comfort by introducing Dow XLATM fiber in woven polyester/ cotton fabrics meant for professional wear. The results indicate that the elastomeric fiber provided additional comfort and that the thermophysiological and sensorial comfort of fabrics was invariant with washing cycles. The presence of elastane component in single jersey fabrics from cotton leads to increase of shear and bending rigidity and compression energy during compresion, measured by KES-F system. Yarn characteristics and evenness significantly affected geometrical roughness [28]. So it is necessary to adapt the different measuring devices and test protocols to compression fabrics. Furthermore, we will compare the different test methods to define thermoregulatory and sensoric properties of compression textiles and provide guidance on the most suitable methods for selection where choices are available to the user. 


\section{Innovation target}

The innovative project aim is to generate specific sizing charts and provide comprehensive information about body proportions as well as postures to enable the SME community to develop compression sports garments with perfect fit and functionality. In addition, by providing digital average body forms this research project enables SMEs to visualize developed garments in common 3D CAD software (e.g. Vidia, Lectra-Modaris). This will save time to market and money. With the knowledge of biomechanics, textile products can be designed to support certain movements, stimulate or just limit them. Such textile products can, for example, contribute to the reduction of the number of injuries in athletes and people with various forms of motion limitation or limit some movements and lead to more rapid rehabilitation.

The design phase comprises calculation of the properties required to a fabric in certain places and directions, especially with regard to strength, deformation and comfort. Therefor modified test protocols to assess thermophysiological properties will be developed. On the basis thereof appropriate materials and textile structures can be selected to reach the desired functional and comfort properties.

\section{References}

[1] H. Schatz, Sports Illustrated, 2002.

[2] A. D. Raeve, Smartfit project, Gent: HoGent, 2012.

[3] "It's gotta be the suit," 8 August 2002. [Online]. Available: www.velonews.com. [Accessed 15 January 2016].

[4] CEN, "NBN EN 13402-3 Size designation of clothes: Body measurements and intervals," NBN, Brussel, 2013.

[5] Eureka project, "New paradigm of processes and market services for garments of obese and elderly people - GarmNet," 2016.

[6] S. Morlock, A. Schenk and M. Harnisch, "Passformgerechte und bekleidungsphysiologisch optimierte Bekleidungskonstruktion für Männer mit grossen unterschiedlicher Körpermorphologien - IGF - Vorhaben 17460N," Hohenstein Institut für Textilinnovationen GmbH, Bönnigheim, 2015.

[7] A. Klepser, A. Gerhardts and B.-M. Wölfling, "Entwicklung von Sportbekleidung für Rollstuhlfahrer unter Berücksichtigung physiologischer und hautsensorischer Einflussfaktoren - IGF -Vorhaben Nr. 17377N," Hohenstein Institut für Textilinnovationen GmbH, Bönnigheim, 2014.

[8] S. Morlock, E. Wendt, E. Kirchdörfer and et al., "Grundsatzuntersuchung zur Konstruktion passformgerechter Bekleidung für Frauen mit starken Figuren, AiF Vorhaben Nr. 15144 BG," BPI Hohenstein; Technische Universität Dresden, Hohenstein, 2009.

[9] A. Giachetti, "Automatic Analysis of D scan of Professional Athletes," in 6th International Conference on 3D Body Scanning Technologies, Lugano (CH), 2015.

[10] M. Kouchi, "Anthropometric methods for apparel design: body measurement divices and techniques," in Anthropometry, apparel sizing and design, Cambridge (UK), 2014, pp. 67-94.

[11] W. Lotens, "Optimal design principles for clothing systems," in Handbook on Clothing, Brussels, 1989, pp. 1701-1715.

[12] U. Schmid and J. Mecheels, "Kräfte an Textilienund Nähten der Kleidung in Abhängigkeit von Körperbewegungen und Kleidungsschnitt," Bekleidung und Wäsche, vol. 2, pp. 77-82, 1981.

[13] S. Choi and S. Ashdown, "3D body scan analysis of dimensional change in lower body measurements for active body positions," Textile Research Journal, vol. 81, no. 1, pp. 81-93, 2011.

[14] E. Bye, K. Labat and M. Delong, "Analysis of body measurement systems for apparel," Clothing and Textiles Research Journal, vol. 24, no. 2, pp. 66-79, 2006.

[15] H. Daanen and P. Reffeltrath, "Function, fit and sizing," in Sizing in Clothing, Cambridge (UK), 2007, pp. 202-219.

[16] C. Ebert, "Neuentwickelder Stretchindex," Sport+Mode, p. 63, 22015.

[17] J. Choi and K. Hong, "3D skin length deformation of lower body during knee joint flexion for practical application of functional sportswear," Appl Ergon, vol. 48, pp. 186-201, 2015.

[18] V. Davies, K. Thompson and S. Cooper, "The effects of compression garments on recovery," $J$ Strength Cond Res, vol. 23, no. 6, pp. 1786-1794, 2009. 
[19] W. Kraemer, S. Flanagan, B. Comstock and e. al., "Effects of a whole body compression garment on markers of recovery after a heavy resistance workout in men and women," $J$ Strength Cond Res, vol. 24, no. 3, pp. 804-814, 2010.

[20] A. Ali, M. Caine and B. Snow, "Graduated compression stockings:Physiological and perceptual responses during and after exercise," Journal of Sports Sciences, vol. 25, no. 4, pp. 413-419, 2007.

[21] W. Kemmler, S. von Stengel, C. Köckritz and e. al, "Effects of compressive stockings on running performance in male runners," J Strength Cond Res, no. 23, pp. 101-105, 2009.

[22] B. Sperlich, M. Haegele, S. Nitsch and e. al, "Bekleidung mit unterschiedlicher Kompressionsfläche hat keinen Einfluss auf die Ausdauerleistungsfähigkeit," Schweizerische Zeitschrift für "Sportmedizin und Sporttraumatologie", vol. 57, no. 4, pp. 132-135, 2009.

[23] R. Duffield and M. Portus, "Comparison of three types of full-body compression garments on throwing and repeat-sprint performance in cricket players," Br J. Sports Med., vol. 41, no. 3, pp. 409-414, 2007.

[24] J. Hu and J. Lu, "Recent developments in elastic fibres and yarns for sportswear," in Textiles for Sportswear, Woodhead Publishing, 2015.

[25] CEN, "CEN TR 16422:2012 - Classification of thermoregulatory properties," European Committee for Standardization, 2012.

[26] M. Harnisch, "Grundsatzuntersuchung zur Leistungssteigerung durch Sporttextilien mit komprimierenden Eigenschaften - IGF - Vorhaben Nr 16868N," Hohenstein Intsitut für Textilinnovation GmbH, Bönnigheim, 2014.

[27] V. P., M. Jose, J. Nieto and M. Blanes, "Comfort analysis of woven cotton/polyester fabrics modified with a new elastic fiber," Tex. Res. J., vol. 79, no. 1, p. 14, 2009.

[28] I. Salopek, Z. Skenderi and J. Gersak, "Investigation of knitted fabric dimensional characteristics," J. Text. CLth. Technol., vol. 56, no. 7, p. 391, 2007.

[29] H. I. f. T. GmbH, "Preliminary test measurement alterations due to movement," HIT, Bönnigheim, 2014.

[30] [Art]. Hohenstein Institut für Textilinnovation, 2014. 